\title{
Behind the Screen: A Case Study of Parent and Student Perceptions of Virtual Learning in Texas, USA
}

\author{
Marsha D. Sowell \\ Department of Teacher and Bilingual Education, Texas A\&M University-Kingsville \\ 700 University Blvd., MSC 196, Kingsville, Texas, 78363, United States \\ E-mail: marsha.sowell@tamuk.edu
}

\begin{abstract}
Due to the COVID-19 pandemic, many public schools opted to begin the Fall 2020 school year with virtual instruction, despite some parent's preference for their children to attend school on campus. Like any product, virtual learning is only as good as the benefits to the customer. In education, the customer is the student, but in the aspect of virtual instruction, the parent is also a customer. This study strives to identify the benefits and challenges revealed by the lived experiences of students learning in a virtual instruction setting and the lived experiences of parents who support their children's virtual instruction during the COVID-19 pandemic. The results of 14 individual, semi-structured interviews reveal that both parents and students perceive virtual instruction to have a number of drawbacks, but also some opportunities for growth. Virtual instruction is also perceived as a learning format with many challenges, including technology and expected parental support.
\end{abstract}

Keywords: virtual instruction, virtual learning, virtual school, virtual education, COVID-19, pandemic

DOI: $10.7176 / \mathrm{JEP} / 12-20-02$

Publication date:July $31^{\text {st }} 2021$

\section{Introduction}

In the summer of 2020, school officials were tasked with a daunting task: determine how to proceed with school in the fall while the world was fighting a pandemic. As school officials worked thru the complicated details of these decisions, the United States Centers for Disease Control and Prevention (CDC) recommended weighing the risks of spreading the novel coronavirus known as COVID-19 against the risks associated with keeping schools closed (CDC, 2020).

Keeping the school doors open for students and teachers meant keeping the door open for the spread of COVID-19. Due to the novelty of the disease, the long-term effects of this virus were still unknown for both children and adults (CDC, 2020). Data indicated school-aged children were less susceptible to experience symptoms, become hospitalized, or die from COVID-19, but some children had been hospitalized and some had died from the virus (CDC, 2020). While children were less likely to be severely impacted by the virus, they were not immune. The risk for adults, however, was still high. Children were able to carry and spread the disease even when they were asymptomatic, thus putting school faculty and staff at greater risk of becoming sick and possibly dying (CDC, 2020). Complicating the situation was the knowledge that schools serve as more than a source of education for America's youth. Schools provide socialization, food, safety, stability, and health care for many students; services that students lose when school buildings close (Gostin \& Wiley, 2020; Wang et al., 2020).

While opening schools would increase the risk of spreading COVID-19, keeping schools closed would cause some students to suffer physically, emotionally, and academically. Recognizing the detriments of closing schools, yet with growing numbers of COVID-19 cases in Texas and the need for school districts to plan for the upcoming school year, the Texas Education Agency (TEA) released school reopening guidelines in July 2020. At that time, the TEA announced that "School systems may offer a remote instruction transition period at the start of the school year" (TEA, 2020a, p. 1). In early September, the TEA clarified that schools could limit access to on-campus, in-person instruction for up to eight weeks and that "[a]s a result, some parents opting for their student(s) to attend on campus may be required to start with remote instruction temporarily" (TEA, 2020b, p. 3). In light of these circumstances, many school districts opted to move to remote or virtual instructional platforms. Learning would continue, but school doors would remain shuttered.

\section{Review of Literature}

Students' current and prior learning suffers when schools are closed. When schools close for seasonal or summer breaks, students experience what is commonly called the 'summer slide'. Based on previous summer slide data, projections indicated that students could lose $30 \%$ to $90 \%$ of learning from the 2019-2020 school year due to school closures in the spring of 2020 (Acevedo et al., 2020; Kuhfeld \& Tarasawa, 2020). Acevedo et al. (2020) further warned that prior to the pandemic, the world was already facing a learning crisis in which over half of low- and middle-income students were "living in Learning Poverty - unable to read and understand simple text by age 10 " (p. 4). Learning loss due to school closures would be greater for low-income students, further widening the achievement gap (Kuhfeld \& Tarasawa, 2020; Van Lacker \& Parolin, 2020). 
Virtual instruction allows school officials to keep the school building closed while continuing to provide instruction, mitigating some impacts of the learning losses. Virtual instruction is a teaching and learning model in which students receive instruction and assignments via an online platform (Toppin \& Toppin, 2016). Virtual instruction has increased in popularity for several years. In 2009, all 50 states and the District of Columbia offered some form of virtual instruction. In that same year, over one million American students participated in virtual instruction (Fernandez et al., 2016). Virtual instruction, however, cannot replicate the value found through in-person or face-to-face learning (Bettinger et al., 2020; CDC, 2020) and may highlight further inequities in education for lower income students: technology access (Champa et al., 2021; Varela \& Fedynich, 2020). Toppin and Toppin (2016) highlighted the ineffectiveness of virtual instruction, reporting that only $27.4 \%$ of virtual students met Adequate Yearly Progress in learning. This may be due, in part, to the fact that many teachers have not been trained to teach in a virtual situation (Champa et al., 2021; Fernandez et al., 2016; Varela $\&$ Fedynich, 2020) and effective virtual instruction requires appropriate application of digital pedagogy (Kong, 2018).

Success in virtual schooling requires strong personal discipline, a trait not all K-12 students possess (Toppin and Toppin, 2016). In a study of Chinese students opting to use virtual instruction, only some students were able to maintain consistent grades between virtual and in-person settings (Fernandez et al., 2016). Wang et al. (2020) pointed out that a lack of personal discipline inherent in a closed school setting would not be alleviated by virtual instruction. Students taking classes virtually tend to be to be less active, spend more time on screens, and ignore schedules when compared to students attending in-person school. In addition to poor learning experiences, these habits lead to poor sleeping and eating, weight gain, and loss of fitness. The additional time virtual instruction requires students to spend on the computer can lead to back pain, damaged eye sight, and increased opportunities to encounter internet addiction, cyberbullying, and exposure to inappropriate content (Kong, 2018). Despite increased time of the computer for virtual learning, teachers report their greatest challenge of virtual learning is decreased student engagement (Champa et al., 2021).

Virtual learning does not alleviate all the issues of school closures either. Through virtual instruction, "every single inequity is now at the surface: access to technology, abusive homes, absent parents, sibling supervision, second language, special needs, drug use, etc." (Varela \& Fedynich, 2020, p. 3). When schools close, students lose access to social support systems such as peers and teachers (Gostin \& Wiley, 2020; Wang et al., 2020). Food insecurity increases as students are not able to access food provided by the school (Gostin \& Wiley, 2020; Van Lacker \& Parolin, 2020).

Parental attitudes regarding virtual instruction also impact their children's attitudes, thus strong schoolparent partnerships are needed for effective virtual instruction (Fernandez et al., 2016; Kong, 2018). Kong (2018) reports that when parents understand virtual instruction, they are more likely to support it. This support, however, usually focuses on virtual instruction as supplemental learning with multimedia and interactive options to boost student motivation. While parents were supportive of virtual instruction, only $61.9 \%$ of parents wanted to provide virtual instruction policies such as time limits and location of using digital devices at home to support learning (Kong, 2018). Champa et al.'s (2021) study further demonstrates the need for parental support in virtual instruction. The teachers responding to Champa et al's survey reported that student engagement increased and teacher workload improved with increased communication between teachers, students, and families.

Like any product, virtual learning is only as good as the benefits to the customer. In education, the customer is the student, but in the aspect of virtual instruction, the parent is also a customer. This study strives to identify the benefits and challenges parents and students perceive in their lived experiences with virtual instruction in response to the COVID-19 pandemic. This study seeks to contribute to the body of literature aiming to better understand the realities of learning in a virtual world to inform educator preparation programs, K-12 teachers, educational leaders, policy makers, and stakeholders on what it means to attend virtual school.

This study aims to understand and reveal the lived experiences of Kindergarten through grade 12 students and the parents who support their learning in a virtual instruction setting during the COVID-19 pandemic. Using the findings of this study, education stakeholders can better prepare to address the learning needs of students and families participating in virtual instruction.

\section{Methods}

Data for this project was collected in the fall of 2020. Seven parents and seven students participated in the study. The six participating families represented the experiences of virtual instruction in second through $11^{\text {th }}$ grades on five campuses in three school districts from different regions in Texas.

\subsection{Data Collection}

This exploratory qualitative case study used semi-structured interviews as the means of data collection. The interviews, conducted either virtually or in-person as per the participant's preference, consisted of questions designed to paint a clear picture of the lived reality of participating in virtual instruction and begin conversations 
about what that reality meant to the participant. In addition to field notes taken during the interview, with consent of each participant, interviews were digitally recorded for later transcription. One participant preferred not to be recorded.

\subsection{Participants}

True to the nature of a case study, participants were selected from a bound system. Each participant was either a parent whose child has experienced virtual instruction in Texas during the Fall of 2020 due to the COVID-19 pandemic, or a student who has experienced virtual instruction in Texas during the Fall of 2020 due to the COVID-19 pandemic.

In March of 2020, all six participating families were forced into virtual instruction due to the pandemic. In August of 2020, all six families were required to start with virtual instruction but then given an option to move into in-person, face-to-face schooling.

Participants Dave and Diana selected to send their children back to face-to-face schooling as soon as possible. Their sixth grade son Daniel and third grade son Dylan, both participants in this study, had attended inperson schooling for two weeks at the time of the interview. Prior to going to the school building, Daniel and Dylan stayed home and completed virtual instruction while both Dave and Diana worked outside the home. During in-person school, the boys both continued to work via virtual instruction within the school building.

Participant Andrea and her husband decided to continue with virtual instruction at the time of the interview and expected to continue through the semester. Both of her daughters, sixth grader Addison and third grader Avery participated in the study. Andrea stayed home to help her daughters with virtual instruction.

Participant Hannah and her husband allowed their daughter to return to school in-person, but their fourth grade son Hudson, also a participant in the study, chose to remain a virtual student to begin the year. Hudson planned to return to face-to-face instruction the week following the interview. Each day Hannah took Hudson to a grandparent's house to complete his virtual school while his parents worked.

Participant Rebecca opted to keep her third grade daughter Riley as a virtual student for the first quarter. Since Rebecca's husband was working from home five days a week and Rebecca only worked outside of the home two days a week, they felt they had the resources to support Riley in virtual education and opted not to take one of the limited seats the school district offered for in-person learning. Riley was also a participant in the study.

Participant Nichole and her husband opted to keep Natalie, their second grade daughter, in virtual instruction through the first quarter. At the time of the interview, they were debating if Natalie should continue virtual instruction or move to face-to-face instruction for the second quarter. Natalie, who also participated in the study, spent her school days at her grandparent's house while her parents worked outside the home.

Participant Brittany, the mother of an $11^{\text {th }}$ grade son who did not participate in the study, was moving between face-to-face and virtual learning for her son. Although she originally sent her son back to in-person instruction while she worked outside the home, he hated the masks, social distancing, and continued reliance on virtual instruction inside the school building. Brittany and her husband decided to allow their son to return to virtual learning without an adult at home during the day on the condition he raise and maintain his grades. Brittany's son returned to virtual school the week after the interview.

\subsection{Data Analysis}

Data analysis for this project followed a grounded theory approach in which codes and themes were gleaned from the data rather than from preexisting ideas (Glaser \& Strauss, 1967). Each interview was transcribed into a Microsoft Word document to facilitate the researcher's coding process and identify common ideas revealed among the participants. The documents were then color-coded by family group with different fonts or styles indicating the different family members. The colors for each transcription matched the pen color of the researcher's field notes hand written during the interviews. After completing the transcriptions, all of the data was printed with wide margins. While reading the data, the researcher coded the data by making notes in the margins. Data reduction then began by cutting pieces of data apart and placing them into piles with similar or matching coding. The data was shifted through multiple times, adapting the piles into themes and categories (Glanz, 2003). The themes were then checked for support from different sources to ensure triangulation.

Trustworthiness in this study was obtained by ensuring credibility and confirmability through triangulation of materials and member checking. Transferability was achieved through purposive sampling and thick description. Dependability was achieved through providing details about the process of data collection, triangulation, and member checking (Lincoln \& Guba, 1985).

\section{Results}

Data analysis for this research study resulted in the identification of four themes discussed below: 1) educational quality, 2) frustrations, 3) benefits, and 4) supports. 


\subsection{Educational Quality}

When discussing educational quality, two categories emerged: academics and experiences. The participants in this study recognized that the term 'education' embraces not only what students learn but the manner in which they learn.

Overall, the parents did not perceive virtual instruction to be as effective as in-person, also referred to as face-to-face, schooling in supporting students' academic learning. Hannah clearly asserted, "I think face-to-face is a better quality instruction." Having experienced both face-to-face instruction and virtual instruction personally, in regards to virtual instruction Nichole said, "I know I was missing out. I felt the lack of - just being, even if you don't answer or ask questions in class - there's something about sitting in a classroom."

Diana, Dave, Brittany and Andrea all noted that their personal children were not getting the same quality of instruction through virtual platforms as they received through in-person, face-to-face formats. Andrea explained that after being forced into virtual school in the spring she noticed a gap in her children's education in the fall:

With the beginning of this year, I saw a lot of struggle just in trying to remember some of the things - there is a lot of recovery at this point. It already feels rushed because we're trying to get to a different point on the scale because we lost so much time. I think it has hurt them.

Despite the perception that virtual instruction is not as effective as in-person, face-to-face schooling, some of the parents were unsure if their children's academics were being harmed by virtual schooling. Hannah said:

I feel like he's done pretty good - but could he have done better? Probably. He's still making good grades. It's not that he's doing bad. But I feel like - would he have done better [in face-to-face]?...They are doing fractions right now and that was hard at first. I feel like he would have learned better face-to-face, but he's doing okay now. It probably has hindered him some, but he's doing okay now.

Although Rebecca thought Riley's education may be hurt by the year of virtual instruction, she was unconcerned, explaining, "We are all probably going to be a year behind at this point next year. I don't think she [Riley], in particular, is having any trouble."

Nichole pointed out that she was concerned about how the current virtual education might impact the student's future education. She mentioned, "We are completing the task, but we're not giving the context as to why it is important." The students seemed to recognize that they were just completing tasks, but they did not demonstrate any concern for this. When asked what they do in virtual school, all seven students simply gave their schedule. Hudson said:

Usually I start at 7:40 in the morning. Do the math, reading, Language arts. What else do I do? Then I do science and social studies and my day ends. Usually ends around three, sometimes earlier. And I constantly have meetings - I have three meetings during the day, but I have small groups other times. I have math, reading, and Language arts generally - but I also have small groups some on different days.

When asked what she does on meetings, Natalie said "the teacher teaches us." The tasks were being completed, but the students did not recognize the learning or engagement needed.

Although students seemed to be just completing tasks in virtual schooling, they did not seem to notice a difference between virtual and face-to-face instruction. As Riley said, "I can't think of anything I'm learning better [in virtual school]. It's pretty much all the same." Hudson, from a different school district, confirmed the schooling was pretty much the same for him too. He said, "I don't really think there is a big difference, a huge difference in how much I'm learning." Hudson did go on to explain that he liked the format of virtual instruction better, however, because "I feel like I can get done with work easier. I think they have a tendency to give me less work. I like that." Daniel clarified that he believed that he could finish faster not because of the content of virtual school, but because of scheduling: "I finish way faster than I would in real school....Like in normal school, they spread it out so you can't just do it all in an hour and say, 'Oh, I'm done! I can go home now!'”

Although the students did not think their educational outcomes would be any different in virtual schooling or face-to-face schooling, most of them recognized a difference in the learning environment. Dylan said virtual schooling was stressful for him because he didn't like having "to rush and get to a meeting and be scared I'm gonna miss it." Addison explained, "I also don't like not being able to be in the classroom. Like, I'm working from home - in a different environment - and it's just not the same." Riley agreed saying:

Virtual has been a bit different and I haven't gotten completely used to it yet. I really like a bunch of things about virtual schooling. I like being able to be done kind of early and then be able to like draw or read or write or color or do crafts or play with my Barbies or something.

In addition to the different environment, both parents and students noted that virtual schooling removed the social interactions students usually enjoy in traditional in-person school. Rebecca explained:

I do like the aspects of face-to-face schooling that we are missing out on right now. I like her being able to see other kids. Being able to be around kids from different backgrounds, and learn how to get along with other students. I think there is a real benefit to that.

Andrea also worried that the lack of social interactions would be detrimental to her children:

But for her age, I think they really just want to play. You know? And that's one thing they talk about a lot is 
that more than anything they miss recess and chasing each other out on the playground. So, that's what I miss the most and that's what I worry about for them the most is that opportunity to be kids and not just taking classes. That's all it feels like right now.

The students feel the lack of social interaction as well. Five of the seven students said they would go back to face-to-face schooling "because I would get to see my friends" (Daniel). Natalie misses talking to people her own age and Dylan wants to go to recess with his friends. Riley misses seeing her friends and having fun in school while Avery says in face-to-face schooling "I would get to be with my friends and it would be easier to learn a lot of stuff." Although Addison would prefer to remain in virtual school due to its flexibility, she noted that without the pandemic, she would still be able to see her friends outside of school.

For both academic reasons and the school experience, every parent said they would prefer to have their children attend in-person, face-to-face schooling. Each parent, for various reasons, felt the educational quality of face-toface schooling was higher. The majority of the students, although not concerned with educational quality, also agreed the educational experience would be better in a face-to-face setting.

\subsection{Frustrations}

The parents and students both experienced frustration over technology glitches and confusion with navigating the virtual curriculum. The parents also expressed frustration with, and gratitude for, the teachers.

Although all of the participants voiced their frustration with technology in some way, they seemed to accept this was just a part of using virtual platforms. Hannah expressed her experience: "Of course, something always doesn't work. Like every day there is something that doesn't work - we've just come to accept that. The video, something doesn't work." Daniel explained his frustrating technology glitch:

There's multiple things I don't like about it [virtual instruction], but the very least is probably I'll turn in an assignment, but then there won't be a grade for it. Then my mom will check [the grading portal] and then she'll get mad at me, like I'm the one who did something. But it's just that the teacher didn't get it or something happened.

Dave elaborated on the situation, "There were times when we redid work three or four times trying to get it to the teacher and they weren't receiving it on their end. That was frustrating for me; it was frustrating for my kid." Students' main frustration consisted of technology glitches that prevented them from joining meetings.

I don't like that sometimes the computer, or whatever I'm using, doesn't work and I miss some of the instructions in the meeting and I have to figure it out myself. Like it freezes or it kicks me out of the meeting and I can't get on, or everything is just staticky (Avery).

Riley, Addison, and Dylan also mentioned connectivity issues causing them to miss meetings.

In addition to technology glitches, these families also experienced confusion with navigating the virtual curriculum. Brittany explained her $11^{\text {th }}$ grader's struggle:

In the beginning, he thought he only needed to be checking [Microsoft] TEAMS. Now he has teachers using Flipgrid, Google Classroom, EdPuzzle, TEAMS, EdGenuity, group projects - how do you do a group project with people you've never seen or met? I'm so frustrated I could scream. He doesn't understand he's a highly intelligent, gifted child. That doesn't mean he knows how to submit all these different things or use all these different programs.

Hannah reported having similar struggles for her fourth grader:

It was quite the learning curve figuring out how to even know what he had to do, how to submit that. Somethings you have to submit, somethings it saves your work and you don't have to submit. To me, that was all kind of confusing. How to check his work - it took awhile, like we weren't even sure what he was getting in and what he was missing.

Hudson added that sometimes his assignments would not show up on the virtual platform until after he had finished school for the day, thus making him work later.

Rebecca had similar difficulties with assignments showing up for Riley. She described:

There's a few times when she [the math teacher] has said there is an assignment there and it's not there. Or it's not working and she can't get it working until three or four in the afternoon and I guess we are still expected to complete it. That's a little frustrating because we would like to be, you know, finished earlier than that. There's been times she's said there is a video you can go watch and I can't find the video anywhere.

Riley came up with a system for dealing with the situation. She explained, "I usually work on my math assignments first so I can find all those little things that she said we are supposed to do but I can't find. So, like I can be like, this thing I'll see about later."

In addition to the confusion of navigating the virtual curriculum, some parents were frustrated by the teacher's lack of support for students in their classes. "He asks the teacher questions and doesn't get a response," Brittany said. Diana explained that when her children had technology issues "certain teachers weren't very helpful. They were like 'Oh, you didn't turn it in. You gotta do it.' They weren't very lenient.” 
In light of the struggles with virtual teaching, Andrea called for teachers to gain help. "They need training! They need help because we don't have time to waste." Rebecca also sympathized with teachers, saying:

I really do appreciate what the teachers are doing, because for them this has got to be difficult. So I really appreciate what they are doing. I hope this is not a forever thing, it just is not sustainable, but I do appreciate how they have stepped up and done what they can do....I know this is new for everybody, so I'm giving grace.

\subsection{Benefits}

While the families did experience frustration with virtual schooling, they also recognized some of the benefits they were receiving due to the use of a new way of learning. The flexibility and ability to personalize learning were seen as benefits to most of the families in this study. Andrea explained:

This has given us an opportunity to find a different part of who we can be. And know how to just turn things off for a minute, and unwind, and relax.... We've figured out how to slow down but still get things done. It's the flexibility piece - at this point it is convenient. We can still do a lot as a family or just nurture some other interests they have and not just be focused on school all the time.

Both parents and students recognized that with virtual schooling students had more flexibility and free time in their schedule. From a logical standpoint, Diana recognized that this allowed their children to "sleep in a little bit and adjust" as needed. Dave also pointed out that "we are going to have a bad weather day Monday. With virtual school, everyone can still log in - so that's good." Hannah took a more personal note and praised the time she was able to spend with her son. With virtual schooling Hannah was able to have lunch with Hudson and he was able to spend more time with his grandparents. Hudson also recognized this benefit, saying, "Then I get to just be with family more often and I have a break in the morning, which I like."

Rebecca liked the freedom the time gave Riley to explore her passions. She said that Riley:

likes to have free time to read, it's like her favorite thing. So that has been great. She has gotten lots of opportunities to just read whenever she wants to...So that's been a nice perk for her. She likes to write too, so she's been writing a book in her free time. It's not really school related, but it has been a learning benefit because she has more free time to kind of do what she likes to do.

Not everyone felt the free time was beneficial. Brittany explained that the frequent breaks result "in kids playing on their phone, playing chess on the computer, watching YouTube. My son literally got nothing done."

Daniel also recognized the detriment of too much free time:

When I was at home I definitely procrastinated a lot more. I would say, 'Okay, I have to start - I have a meeting at this time. Then I have a meeting here and a meeting here.' But after I do all those meetings I should give myself like two hours to just hang out because that's a lot of work. I would do my two hours, then I'd say, 'Okay, let's start working' and my brain would say, 'No, you can do another hour!' Then I'd sit there for another two hours. And then I'd look at the clock and my mom was almost home and I'd say, 'Uh, oh! Mom's gonna be home!' and I'd do my work (Daniel).

Nichole recognized that the flexibility allowed her family be personalize learning for Natalie:

We set the schedule. If we think she is going to do better doing math first thing in the morning when she is fresh after she has had breakfast, then we do math in the morning because that's the subject we think she struggles with and then let everything else go through the afternoon....It gives us the flexibility - when she's hungry or she's fidgety and not having it right now - or she's just not having a good day. Then you can take a break. A good break - a 30 minute break, an hour break. And not just the push, push, push, push, push from eight to $3: 30 \mathrm{pm}$ or whatever it is now. So the flexibility is nice that it's stretched out all day (Nichole).

Rebecca also recognized that the virtual format allowed Riley to personalize her instructional day.

I do like that she's taken on a lot of responsibility for her own learning and own assignments. I feel like that's really helped her - just the responsibility of it. I think it's kind of cool to see her being able to figure it out... We have noticed that she tends to like to work on something and take a break and work on something and take a break. And I kind of like letting her see what works for her. If that works better for her learning style - maybe in the future when she is in college and you have that kind of flexibility to set your own schedule like that - it might benefit her.

Like Rebecca, Andrea recognized the possible future benefits of her girls engaging in virtual schooling:

They know how to navigate an online course. They know how to work with self-paced content with an assignment they have to do. They know how to ask for help. I think that is one of the really big things - in this setting they have to ask....There's a lot of growth in them as learners. Just in a different style and a different system. I'm really just fascinated by that - more than anything - they have this opportunity to learn in a completely different way and so far they are doing pretty well with it.

From the flexibility of free time and exploring interests to the ability to personalize learning and navigate virtual platforms, parents and students both recognized benefits from virtual school. 


\subsection{Support}

Both parents and students recognized the need for direct adult supervision and support in virtual schooling. Their perspectives on this element, however, were very different. While parents were frustrated and searching for ways to help their children, the children believed the parents provided everything they needed.

\section{Parents felt unqualified.}

Nichole explained that she did not feel qualified to help her daughter in the best way possible:

We as the parents and grandparents don't understand some of the language that is used by the teachers. Sometimes the way they are teaching things is new from 40 years ago, 30 years ago when I was in school, 50 years ago when my parents were in school. So you are trying to teach her the way the teacher shows and the lessons, but yet if you don't understand.... So it is trying to teach yourself to teach your child the way the school is teaching them and not giving them too many options that they get lost....We aren't teachers. We're engineers, we're librarians, we're homemakers - you know. So that's the most frustrating part sometimes - that we just don't have the skillset.

As a parent of a gifted high school student, Brittany felt the same way. She exclaimed, "I can't help him with calculus. I didn't take calculus!”

Hannah expressed concerns for the grandparents helping her son:

And the poor grandmas, they need a break! It's not that it is hard, but they are not familiar - they use a million different apps and things. You can't access them all from one place. You have to go to all these different places. It's confusing, even for somebody who is pretty comfortable with technology.

Diana was frustrated by her inability to be at home to help her children. She claimed:

Leaving them home all day was, I think it was a downfall on our end. I mean, if you have a stay-at-home Mom or a parent or an adult - you are getting assistance from an adult versus if you are working. They are expected to be online at certain times, they are expected to participate, they are expected to turn in work still. So they are navigating - my kids are navigating - my eight year old was doing it by himself. So we weren't there to make sure it was being done appropriately, they were reading instructions appropriately, like other kids may have had the benefit of. So I feel like that was - us working and leaving them home to do it alone was frustrating.

Andrea explained, however that even being home she did not feel like she knew how to help her girls in virtual school. She said, "I think the hardest part is feeling like I am doing enough to support them. But sometimes they just don't need it, so I don't know what I am supposed to be doing."

Despite not being sure of what to do to support their children, these parents tried to provide structure and support to virtual school. Brittany lamented, "For kids with poor time management, which he [her son] does have, it's hard for them. He keeps begging for structure. He's always the child who needs structure." Many parents did what they could to fill this need for structure. Andrea said:

I think the most I can say I've done is to help them with time management, with organizing their day. They know what their teachers expect, they know what their assignments are, they know how to get them done, but balancing it and looking at the clock and realizing 'It's four o'clock, oh my goodness, and I didn't do three things because I started gazing at the TV for awhile...' kind of reeling them back in is probably what I do most of the time. Just helping them keep the focus and organizing their day and keeping a checklist of things and making sure they check off the list. So I'm the manager; that is what I feel like.

Diana and Rebecca would set alarms to remind their children to get onto their meetings. Dave would call Dylan right before meetings to remind him to get on the computer.

Most of the parents would also review their children's work. Although they worked all day, in the evening, Dave and Diana would try to check all the schoolwork for the day, going through to make sure assignments were completed and submitted and helping the boys when needed. That was also the last action of Riley's school day as Rebecca explained, "At the end of the day, I check them to make sure she completed everything and turned it in. Of course, if she needs help with anything she asks one of us and we help her."

Although the parents were frustrated with helping their children and unsure of how to help their children, the children did not seem to notice. All seven students recognized that their first line of support came from their parents. "If there's stuff I don't know I just don't do it and I wait 'til my parents get home," said Dylan. Addison explained, "If it's a problem that my mom can help me with then I'll ask my mom. If it's a problem my dad can help me with then I ask my dad." "When I have trouble, (I ask) my mom. And then if my mom doesn't understand it because she was taught math differently and things differently, my sister helps," Avery stated. Hudson and Natalie both listed 'Mom' as their first helper, but grandparents, who they stay with during the day, as helpers as well.

Overall, most of the parents answered the interview questions with a broader outlook than the students. While parents were concerned about how this time in virtual school would impact their children in the long term, students simply responded as virtual schooling is just what is happening now. While the themes overlapped, the concerns were very different in the two groups. In terms of social interaction, for example, Andrea said, "I didn't 
want her [Avery] to miss out on an opportunity to develop those friendships." Avery, however, said, "I miss my friends a lot and being able to play and sit with them at lunch." These different outlooks tended to give parents a more negative view of virtual schooling than students' views.

\section{Discussion}

Both parents and students perceive virtual instruction to have a number of drawbacks, but also some opportunities for growth. Virtual instruction is also perceived as a learning format with many challenges.

\subsection{Drawbacks of Virtual Instruction}

It is widely believed that virtual instruction cannot replace the quality of an in-person, face-to-face education (Bettinger et al., 2020; CDC, 2020). The parents in this study tended to agree that face-to-face instruction is more effective than virtual instruction. They cited ineffective videos, unresponsive teachers, and their own lack of deep understanding in subject matter and pedagogy as reasons they believed their children's education was suffering in virtual learning. While the students did not vocalize any recognition of the differences in their learning between the two formats, some of their comments indicated they might be feeling the differences. Avery noted she would like to return to face-to-face learning in part because "it would be easier to learn a lot of stuff." However, the students did not feel like they were missing out on their education. Several students noted that the format of the class made the classes easier and faster without a difference in content or expectations. Daniel explained, "in normal school they spread it out so you can't just do it in an hour". Riley's words summarize the students' attitudes regarding virtual school versus face-to-face school: It's pretty much all the same.

"The same" was recognized as a problem for Nichole. She noted that sometimes the work being completed felt more like students were just completing tasks rather than learning. Students seemed to confirm this idea by listing the tasks or meetings they accomplished in virtual school rather than discussing the content or processes they learned.

All seven parents acknowledged that schools teach more than just academics. All seven parents were concerned about the social interactions their children were missing through virtual instruction. As Rebecca voiced:

I do like the aspects of Face-to-Face schooling that we are missing out on right now. I like her being able to see other kids. Being able to be around kids from different backgrounds and learn how to get along with other students. I think there is a real benefit to that.

The students agreed that virtual schooling was making them miss their social interactions. Five of the seven students would opt to go back to face-to-face schooling just on the basis of being able to see their friends and one student would remain virtual with the knowledge that she would be able to see her friends outside of school. The students also recognized there was something else missing in virtual school compared to face-to-face school although they were not able to vocalize it well. Addison explained, "I also don't like not being able to be in the classroom." Like these participants, Gostin and Wiley (2020) and Wang et al. (2020) recognize that one drawback of schools closing is that students lose access to their social support systems consisting of teachers and peers.

\subsection{Growth Opportunities Gained from Virtual Instruction}

While no parents or students voiced any recognition of a direct academic benefit from virtual instruction, they did note several non-academic benefits. Several parents recognized that these benefits stemmed from the virtual setting through learning to navigate online classes, manage unstructured time effectively, and discovering student's personal learning style. The flexibility of online learning also allowed some families to rearrange the day to better accommodate learning needs. While no students in this study recognized these learning opportunities, they did see the value of the free time gained in virtual instruction.

Due to the flexibility of the virtual classroom, many parents and students recognized the time allowed to leave the computer and the classroom and explore other interests such as reading, writing, spending time with family, or just learning to relax. The students did not note that this opportunity was a growth experience, but rather an enjoyable use of their time.

It is important to note, that this free time and flexibility was not a benefit for all students. Brittany pointed out that children with poor time-management skills would not thrive in this flexible environment. The parents in this study noted that the more structured the expectations, whether structure was provided by the student, school, or parent, the more successful the student was in virtual schooling. This was further supported by Daniel, who enjoyed the free time but admitted that without someone home to keep him on schedule he was prone to procrastination and not completing his work.

\subsection{Challenges of Virtual Instruction}

Parents and students differed in what they recognized as challenges to their virtual schooling. When asked about their frustrations, parents focused on issues they perceived as being preventable by teachers. Students, on the 
other hand, focused on issues that prevented them from completing work in a timely fashion, regardless of the nature or cause of the issue.

Parents were upset when teachers did not answer questions promptly or at all, when the organization of the virtual classroom was confusing, and when teachers did not show leniency when technology did not work. Andrea voiced this frustration and what she recognized as the solution: "They [teachers] need training! They need help because we don't have time to waste." Teacher training is vital for effective virtual teaching (Kong, 2018). Due to the pandemic, however, many teachers have not been trained to teach in a virtual setting (Fernandez et al., 2016; Varela \& Fedynich, 2020). Students, on the other hand, focused on the issue or blamed their own shortcomings for technological issues. For example, Riley did not complain that her teacher did not post assignments on time, rather she just referred to the missing posts as "little things she said we are supposed to do but I can't find."

It is important to note that although the parents were frustrated with the teachers, they also recognized virtual teaching was a new challenge to the teachers as well. Most parents purposefully tried to extend grace and understanding to teachers as they learned this new way of teaching. As Rebecca explained, "I know this is new for everybody, so I'm trying to give her [math teacher] grace." Because no student indicated that they were frustrated with their teachers over technology, it could be assumed that the children were not picking up on their parent's frustration in this area. While the parents may not recognize the lesson on grace they model, their children are learning it.

Aside from teacher issues, parents did recognize that the technology itself was sometimes a hindrance, but did not focus on that issue. As Hannah sighed, "Every day there is something that doesn't work - we've just come to accept that." While students, too, accepted technology issues, they voiced much more frustration in this area. As Avery said, "I don't like that sometimes the computer, or whatever I'm using doesn't work."

The expectation of parental support of virtual learning was also recognized as a challenge for the parents, but not for students. Parents' attitudes and support impact the effectiveness of virtual instruction (Fernandez et al., 2016; Kong, 2018). The parents in this study recognized and were frustrated in their role in supporting their children's virtual schooling, but none of the students seemed to recognize the frustration or the parent's struggle in supporting them.

All of the parents in this study wanted to help their children succeed in virtual schooling. They pointed out that they created schedules and set timers, they helped navigate technology, answered questions and checked work. However, many parents believed this was not enough.

Most parents voiced their frustration at not being able to provide the quality of support needed to help their children continue to be successful in school. Parents were at a loss of what they should do to help, were unavailable due to outside work, and did not feel knowledgeable enough to help. As Brittany said, "I can't help him with calculus. I didn't take calculus!" Nichole summarized, "we just don't have the skillset."

These feelings of inadequacy left many parents with a feeling of guilt. This came across when parents were not able to be at home with their children. As Diana explained, "us working and leaving them home alone to do it alone - was frustrating." Even when he could be present, if he was not able to figure out how to help his children, Dave said it was "frustrating for me. It was frustrating for my kid". Brittany added, "I'm so frustrated I could scream." Andrea lamented, "I don't know what I'm supposed to be doing." While the parents felt guilt at not doing enough to help their children, no child indicated they felt their parents did not do enough. When asked where they went for help, no child hesitated in answering Mom and Dad.

The students only recognized that their parents helped them when they needed help. Six of the seven participants said that if they needed help during the day, the parent or grandparent available was their first person to turn to. Although Hudson was with his grandparents most days, he said he would wait to ask his Mom questions. Even Dylan showed no hesitation in saying that if he didn't understand something he would just wait until his parents came home.

\section{Conclusions}

Although parents are concerned about the quality of academic learning in a virtual setting, they recognize the balance of the non-academic benefits. Students did not show any concern about the quality of their education. Most of the parents and students were comfortable with this balance between concerns and benefits in light of the current situation with the pandemic. Parents recognized that although academics might be suffering, everyone is in the same situation and therefore their child should not be falling behind their peers. Students just wanted to see their friends and the computer to work. Although together Rebecca and Riley have chosen to remain in virtual schooling for now, Rebecca explains, "I hope this is not a forever thing, it just is not sustainable".

\section{Limitations and Recommendations for Future Research}

As was previously noted, there were no single-parent homes represented within this study. Additionally, there 
were no low-income families represented within this study. These facts stand as limitations to this study's transferability and should set the stage for future research. Although there was a wealth of information gathered from this group of participants, the study should be replicated with a greater variety of voices and a broader range of school districts and regions. Furthermore, as stakeholders gain more experience in virtual schooling, the experiences will change. As such, longitudinal studies of stakeholder's perspectives of virtual schooling are recommended. More voices and longer engagement will help researchers paint a more diverse and complete picture of virtual instruction.

\section{References}

Acevedo, J.P., Hasan, A., Goldenberg, D., Iqbal, S.A., \& Geven, K. (2020, June). Simulating the potential impacts of COVID-19 school closures on schooling and learning outcomes [policy research working paper]. World Bank Group, Education Global Practice. http://pubdocs.worldbank.org/en/798061592482682799/covid-and-education-June17-r6.pdf

Bettinger, E., Fairlie, R.W., Kapuza, A., Kardanova, E., Loyalka, P., \& Zakharov, A. (2020, April). Does edTech substitute for traditional learning? Experimental estimates of the educational production function (working paper 26967). National Bureau of Economic Research. Retrieved September 19, 2020 from https://www.nber.org/papers/w26967.

Centers for Disease Control and Prevention (CDC). (2020, September 1). Operating schools during COVID-19: CDC's considerations. Retrieved September 18, 2020 from https:/www.cdc.gov/coronavirus/2019ncov/community/schools-childcare/schools.html\#anchor_1597871545636.

Champa, T., Waterbury, T., \& McQuinn, A. (2021). Utilizing the pandemic disruption to identify distance learning challenges. The Quarterly Review of Distance Education, 21(4), 51-63.

Fernandez, H., Ferdig, R.E., Thompson, L.A., Schottke, K., \& Black, E.W. (2016). Students with special health care needs in K-12 virtual schools. Educational Technology \& Society, 19(1), 67-75.

Glanz, J. (2003). Action research: An educational leader's guide to school improvement. Christopher-Gordon Publishers, Inc.

Gostin, L.O., \& Wiley, L.F. (2020). Governmental public health powers during the COVID-19 pandemic: Stay at home orders, business closures, and travel restrictions. JAMA. https://jamanetwork.com/journals/jama/fullarticle/2764283

Kong, S. (2018). Parents' perceptions of e-learning in school education: Implications for the partnership between schools and parents. Technology, Pedagogy and Education, 27(1), 15-31, https://doi.org/10.1080/1475939X.2017.1317659

Kuhfeld, M. \& Tarasawa, B. (2020). The COVID-19 slide: What summer learning loss can tell us about the potential impact of school closures on student academic achievement. https:/www.nwea.org/content/uploads/2020/05/Collaborative-Brief_Covid19-Slide-APR20.pdf

Lincoln, Y. \& Guba, E. (1985). Naturalistic Inquiry. Sage Publications.

Texas Education Agency (TEA). (2020a, July 21). 20-21 school reopening guidance summary. https:/tea.texas.gov/sites/default/files/covid/SY20-21-School-Reopening-Brief.pdf

Texas Education Agency (TEA). (2020b, September 2). SY 20-21 public health planning guidance. https://tea.texas.gov/sites/default/files/covid/SY-20-21-Public-Health-Guidance.pdf

Toppin, I.N., \& Toppin, S.M. (2015). Virtual schools: The changing landscape of K-12 education in the U.S. Education and Information Technologies, 21(6). https://doi.org/10.1007/s10639-015-9402-8

Wang, G., Zhang, Y., Zhao, J., \& Jiang, F. (2020). Mitigate the effects of home confinement on children during the COVID-19 outbreak. The Lancet, 359(10228), p. 945-947. https://doi.org/10.1016/S0140$6736(20) 30547-X$ 